\title{
Medullary Edema and Enhancement with a Straight Upper Border in Cases of Dural Arteriovenous Fistulas
}

W e read the recent article by Copelan et al, "Dural Arteriovenous Fistulas: A Characteristic Pattern of Edema and Enhancement of the Medulla on MRI" with great interest. The authors describe an unusual but characteristic imaging appearance of patchy medullary edema and enhancement with areas of sparing in cases of dural arteriovenous (AV) fistulas.

We previously encountered a similar case of a patient with edema and abnormal patchy enhancement in the medulla on MR imaging with initial misdiagnosis and treatment for neuromyelitis optica. Subsequent DSA demonstrated an arteriovenous fistula with an arterial feeder from the posterior division of the right middle meningeal artery draining into a tortuous transcerebellar vein into a mildly distended varicose anterior spinal vein (Figs 1 and 2). We also note that similar to the cases described by Copelan et al, the edema and enhancement pattern in the medulla demonstrate a characteristically straight upper border (Fig 3). It has previously been reported that dural AV shunts develop at the site where the bridging veins penetrate the dura and then reflux into the pontomesencephalic and anterior medullary systems, potentially resulting in brain stem or cerebellar venous ischemia ${ }^{2}$ and likely accounting for the straight upper border of edema due to a vascular etiology. We believe that the presence of medullary edema and enhancement with a straight upper border should alert the radiologist to the possibility of an underlying dural AV fistula.

\section{REFERENCES}

1. Copelan AZ, Krishnan A, Marin H, et al. Dural arteriovenous fistulas: a characteristic pattern of edema and enhancement of the medulla on MRI. AJNR Am J Neuroradiol 2018;39:238-44 CrossRef Medline

2. Alvarez H, Sasaki-Adams D, Castillo M. Resolution of brainstem edema after treatment of a dural tentorial arteriovenous fistula. Interv Neuroradiol 2015;21:603-08 CrossRef Medline

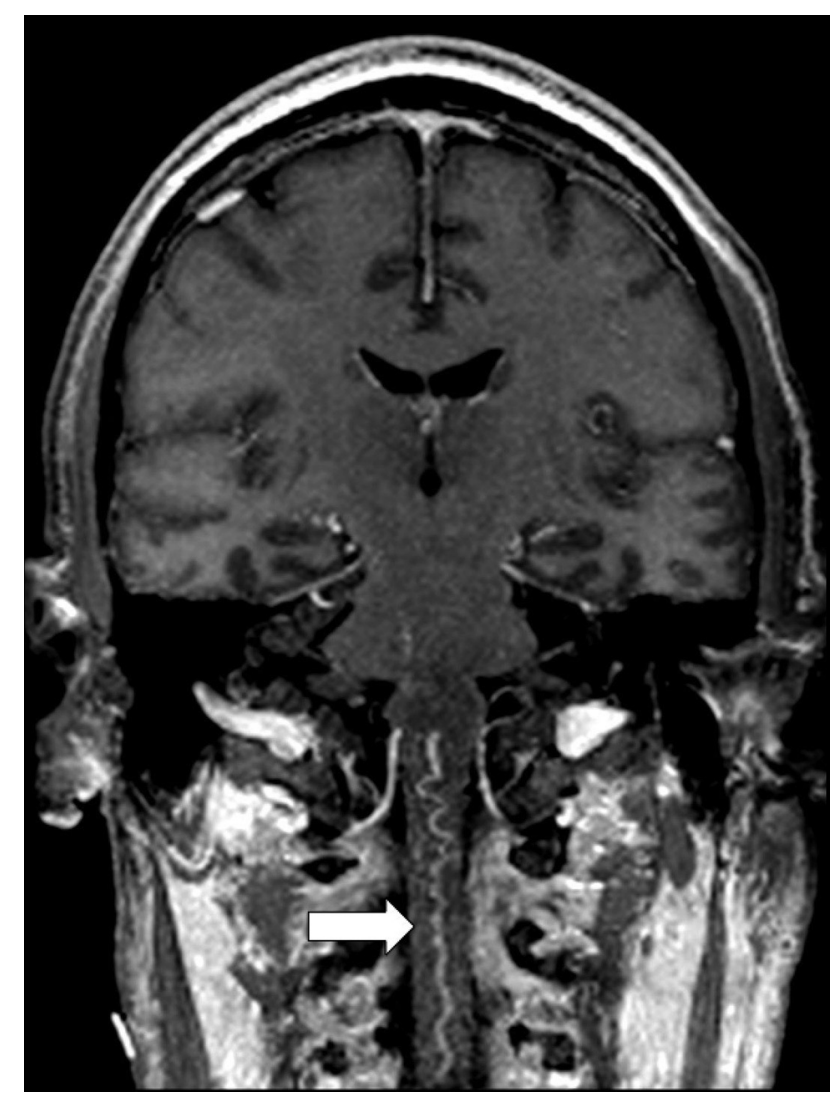

FIG 1. Coronal Tl postcontrast MIP image demonstrates the anterior spinal vein, which is distended and mildly varicose.

$$
\begin{array}{r}
\text { D. Byrne } \\
\text { J.P. Walsh } \\
\text { Department of Radiology } \\
\text { Mater Misericordiae University Hospital } \\
\text { Dublin, Ireland } \\
\text { T. Lynch } \\
\text { Dublin Neurologic Institute, Department of Neurology } \\
\text { Mater Misericordiae University Hospital } \\
\text { Dublin, Ireland } \\
\text { E.C. Kavanagh } \\
\text { Department of Radiology } \\
\text { Mater Misericordiae University Hospital } \\
\text { Dublin, Ireland } \\
\text { School of Medicine } \\
\text { University College } \\
\text { Dublin, Ireland }
\end{array}
$$




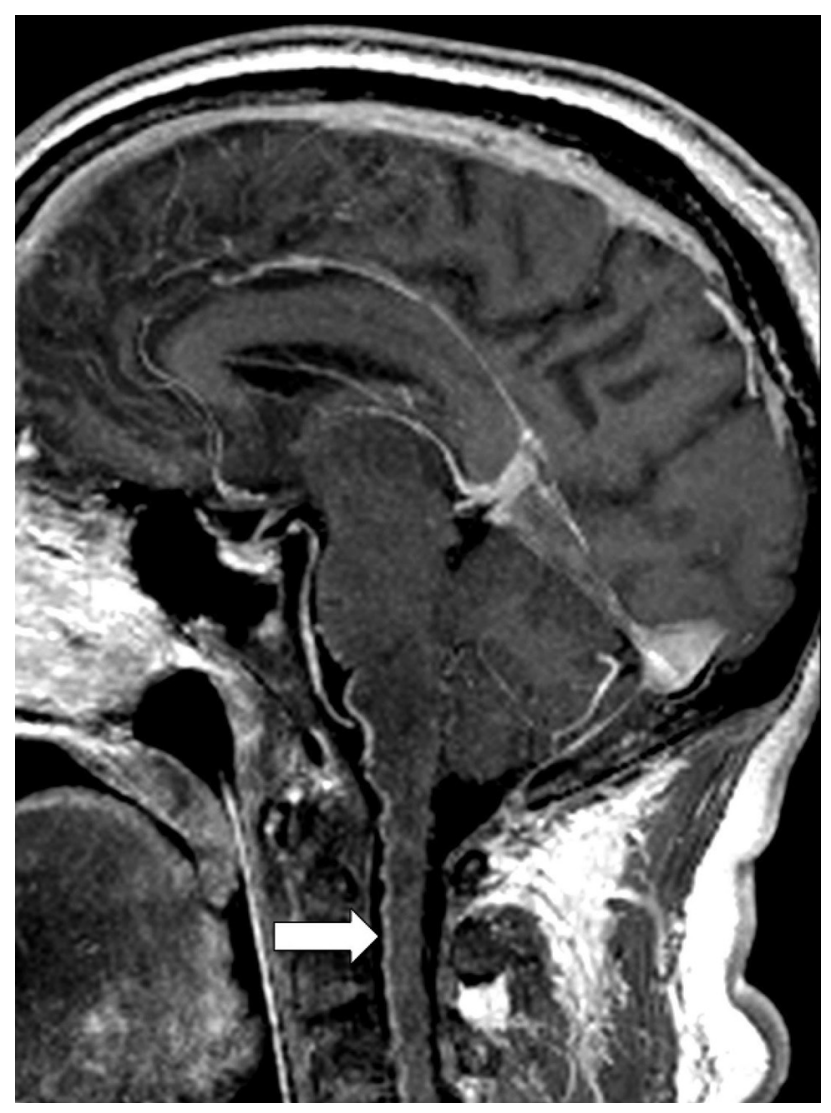

FIG 2. Sagittal T1 postcontrast MIP image demonstrates the anterior spinal vein, which is distended and mildly varicose.

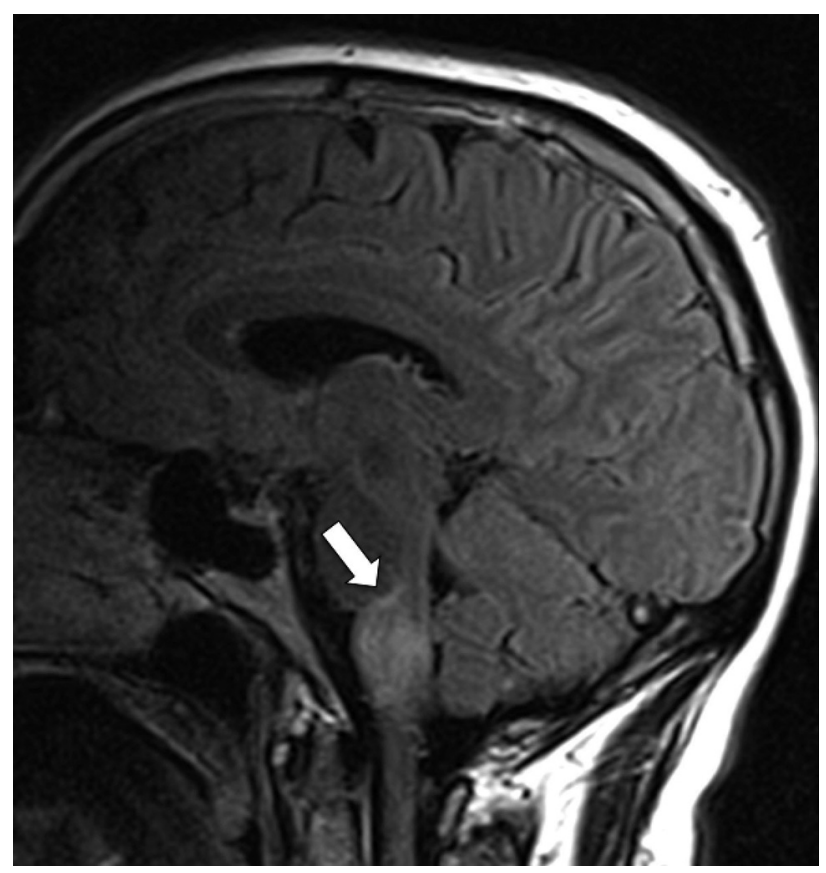

FIG 3. Sagittal FLAIR demonstrates medullary edema with a straight upper border. 